Journal of The Magnetics Society of Japan Vol. 13, Supplement, No. S1 (1989)

(C) 1989 by The Magnetics Society of Japan

\title{
SOFT MAGNETISM OF Fe-Cu THIN FILMS WITH NON-EQUILIBRIUM PHASE DEPOSITED BY ION BEAM SPUTTERING
}

\author{
Toyoaki HIRATA* and Masahiko NAOE**
}

* Osaka Vacuum, Ltd., 7-775, Ootori-Higashi-machi, Sakai,

Osaka 539, Japan

** Dept. of Physical Electronics, Tokyo Institute of Technology, 2-12-1, O-okayama, Meguro-ku, Tokyo 152, Japan

\begin{abstract}
The requirements of the soft magnetic thin films are to have large saturation magnetization $4 \pi \mathrm{Ms}$, small coercivity $\mathrm{Hc}$, enough high permeability, finite electrical resistivity, etc. The pure iron thin films with the $\mathrm{Cu}$ content $\mathrm{X}_{\mathrm{Cu}}$ of 0 at.\% $\mathrm{Cu}$ did not show any clear peaks. The peaks became clearer gradually as $\mathrm{X}_{\mathrm{Cu}}$ increased. The structure of the $\mathrm{Fe}-\mathrm{Cu}$ thin films was amorphous-like, bcc and fcc phases for $\mathrm{X}_{\mathrm{Cu}}$ in ranges of $0-10,10-40$ and more than 40 at.\%, respectively. On the other hand, $4 \mathrm{Ms}$ decreased monotonically as $\mathrm{X}_{\mathrm{Cu}}$ increased. However, $4 \pi \mathrm{Ms}$ decreased remarkably when $\mathrm{X}_{\mathrm{Cu}}$ became more than 50 at.\%.

The coercivity $\mathrm{Hc}$ of the film thickness of $0.4 \mu \mathrm{m}$ showed the lowest value of $0.3 \mathrm{Oe}$ at $\mathrm{X}_{\mathrm{Cu}}$ of 32.8 at.\% where $4 \pi \mathrm{Ms}$ was 11.4 KGauss. The films exhibited the excellent thermal stability and corrosive resistance.
\end{abstract}

\section{INTRODUCTION}

The high-quality thin films of $\mathrm{Fe}-\mathrm{Cu}$ system seemed to be useful for soft magnetic layers in the thin film head and the perpendicular magnetic recording media. Iron and copper scarcely have any solid solutions by melting[1]. Sputtering is one of the techniques useful for quenching the vapor phase and, in addition, for depositing magnetic layers in preparation of thin film heads. Especially, the Ion Beam Sputtering (IBS) is the promising one since the growing film on the substrate is in the very low gas pressure during film deposition.

The requirements of the soft magnetic thin films are large saturation magnetization $4 \pi \mathrm{Ms}$, small coercivity Hc, enough high permeability, finite electrical resistivity, etc. For the $\mathrm{X}$ ray diffraction diagrams of the $\mathrm{Fe}-\mathrm{Cu}$ thin films deposited by the IBS, the pure iron thin films with the $\mathrm{Cu}$ content $\mathrm{X}_{\mathrm{Cu}}$ of 0 at.\% did not show any clear peaks. The peaks became clearer gradually as $\mathrm{X}_{\mathrm{Cu}}$ increased. The structure of the $\mathrm{Fe}-\mathrm{Cu}$ thin films was amorphous-like, bcc and fcc phases for $\mathrm{X}_{\mathrm{Cu}}$ in ranges of $0-10,10-40$ and more than 40 at.\%, respectively. On the other hand, $4 \pi M s$ decreased monotonically as $\mathrm{X}_{\mathrm{Cu}}$ increased. However, 4 Ms decreased remarkably when $\mathrm{X}_{\mathrm{Cu}}$ became more than 50 at.\%. The $\mathrm{S} / \mathrm{N}$ ratio in moessbauer effect spectra decreased with increase of $\mathrm{X}_{\mathrm{Cu}}$. The positional change of 6 absorption lines could not found out for $\mathrm{X}_{\mathrm{Cu}}$ at least in the range of 0 to 15.3 at.\%. The internal magnetic field doesn't change with the difference in composition in the region of bcc-dominant phase, though the dispersion of the internal magnetic field becomes larger with increase of $\mathrm{X}_{\mathrm{Cu}}$. The correlation between the magnetic properties and the film structure implied that the bcc phase and the fcc one are predominant in the lower and higher ranges of $X_{C u}$, respectively, based on the simple dilution law. On the contrary, Hc depended strongly and remarkably on $\mathrm{X}_{\mathrm{Cu}}$. $\mathrm{Hc}$ of the films with thickness of $0.4 \mu \mathrm{m}$ showed the lowest value of 0.3 Oe at $\mathrm{X}_{\mathrm{Cu}} 32.8$ at.\%, where $4 \mathrm{Ms}$ was 11.4 KGauss. The $\mathrm{Fe}-\mathrm{Cu}$ thin films exhibited the excellent thermal stability and corrosive resistance, though they were in non-equilibrium[2]. 


\section{EXPERIMENT}

Figure 1 shows the Dual Ion Beam Sputtering (DIBS) apparatus[3] which was used for this study. This apparatus has two ion sources. The lower one is for sputtering the target (named sputtering ion source, and the upper one is for bombarding the film surface on the substrate (named bombarding ion source). The cover glasses and glass slides were used as a substrate. The bombarding ion source was used for discussing the effect of bombarding the film surface by the high-energy ions from the bombarding ion source.

The target used for preparing the Fe$\mathrm{Cu}$ thin films is shown in Fig.2. The composition of the $\mathrm{Fe}-\mathrm{Cu}$ thin films was controlled by changing the ratio of the iron area to the copper one of the target. The acceleration voltage of sputtering argon ions ( $\mathrm{Vmg}$ ) was $500 \mathrm{~V}$ and that of bombarding argon ions (Vsg) was in the range of 80 to $155 \mathrm{~V}$.

The composition of the thin films was analyzed by the Electron Probe

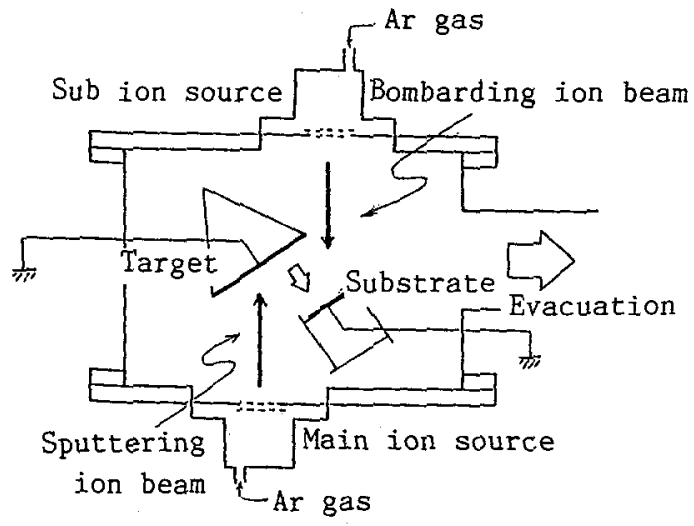

Fig. I Dual Ion beam Sputtering Apparatus

Microanalysis. The structure of the $\mathrm{Fe}-\mathrm{Cu}$ thin films were examined by the $\mathrm{X}$-ray diffractometry--Cu-Ka. Magnetic properties, such as saturation magnetization and coercivity, were evaluated by using the Vibrating Sample

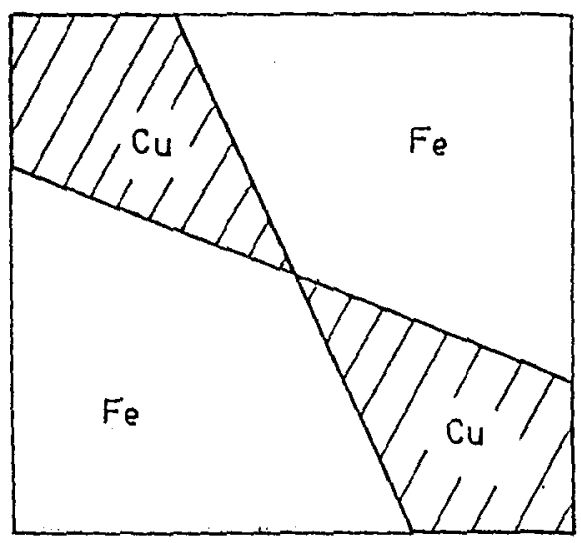

Fig. 2 Fe-Cu compound tärget

Magnetometer (VSM). Moesspauer spectra were obtained by using 57 Co radiation source under the uniform acceleration mode.

\section{RESULTS AND DISCUSSION}

Figures 3 and 4 show the dependence of the $X$-ray diffraction patterns of the Fe-Cu films deposited by the IBS on the $\mathrm{Cu}$ content $X_{C u}$. According to these $X$-ray diffraction patterns, the pure iron thin films with $\mathrm{Cu}$ content $\mathrm{X}_{\mathrm{Cu}}$ of 0 at.\%. did not show any clear peaks. The peaks became clear gradually as $X_{C u}$ increased. The crystal structure of the Fe-Cu thin films was amorphous-like, bcc and fcc phases for $X_{C u}$ in ranges of $0-10,10-40$ and more than 40 at. $\%$, respectively. The dependence of the saturation magnetization $4 \pi \mathrm{Ms}$ on the $\mathrm{Cu}$ content $\mathrm{X}_{\mathrm{Cu}}$ is shown in Fig.5. $4 \pi \mathrm{Ms}$ decreased along the simple dilution law monotonically as $X_{C u}$ increased up to about 50 at.\%. Furthermore, $4 \pi \mathrm{Ms}$ decreased remarkably when $\mathrm{X}_{\mathrm{Cu}}$ became more than 50 at.\%. It is found out that comparing the $\mathrm{Cu}$ content dependence of the crystal structure and the saturation magnetization, the bcc phase is dominant in the region subject to the simpie diution law, wille the icc phase is dominant in the region where $4 \pi \mathrm{M}$ is smaller than the value estimated due to that. 


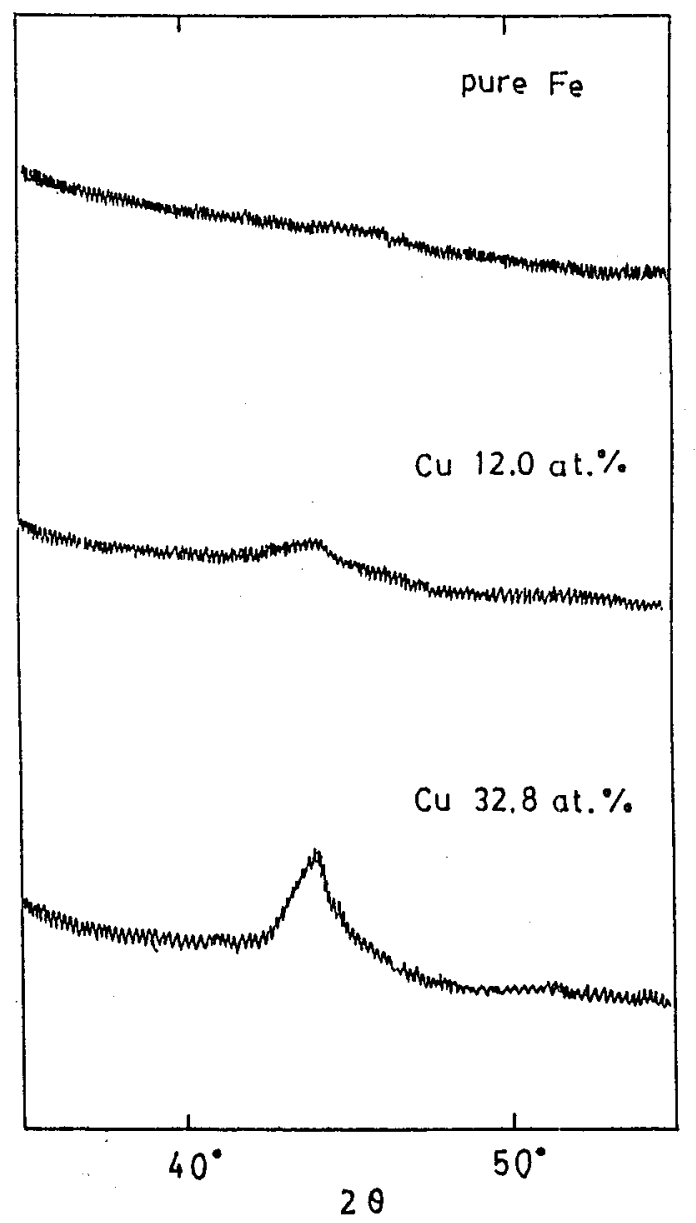

Fig.3 Dependence of X-ray diffraction diagrams on $\mathrm{Cu}$ content (Part 1 )

In Fig.6, the dependence of coercivity $\mathrm{Hc}$ on the $\mathrm{Cu}$ content $\mathrm{X}_{\mathrm{Cu}}$ is shown. Hc decreased as $\mathrm{X}_{\mathrm{Cu}}$ increased. At $\mathrm{X}_{\mathrm{Cu}}$ of 32.8 at.\%, the minimum value, $\mathrm{Hc}$ of $0.3 \mathrm{Oe}$, was obtained. $4 \pi \mathrm{Ms}$ of this thin film was $11.4 \mathrm{KG}$. $\mathrm{Hc}$ began to increase when $\mathrm{X}_{\mathrm{Cu}}$ increased furthermore. Consequently, it can be thought that $\mathrm{HC}$ becomes smallest at $\mathrm{X}_{\mathrm{Cu}}$ of about 33 at.\%.

In Fig.7, it is shown that how Moessbauer spectra changed along the change of the composition of the $\mathrm{Fe}-\mathrm{Cu}$ thin films. The $S / N$ ratio in Yoessbauer effect deteriorated since the number of

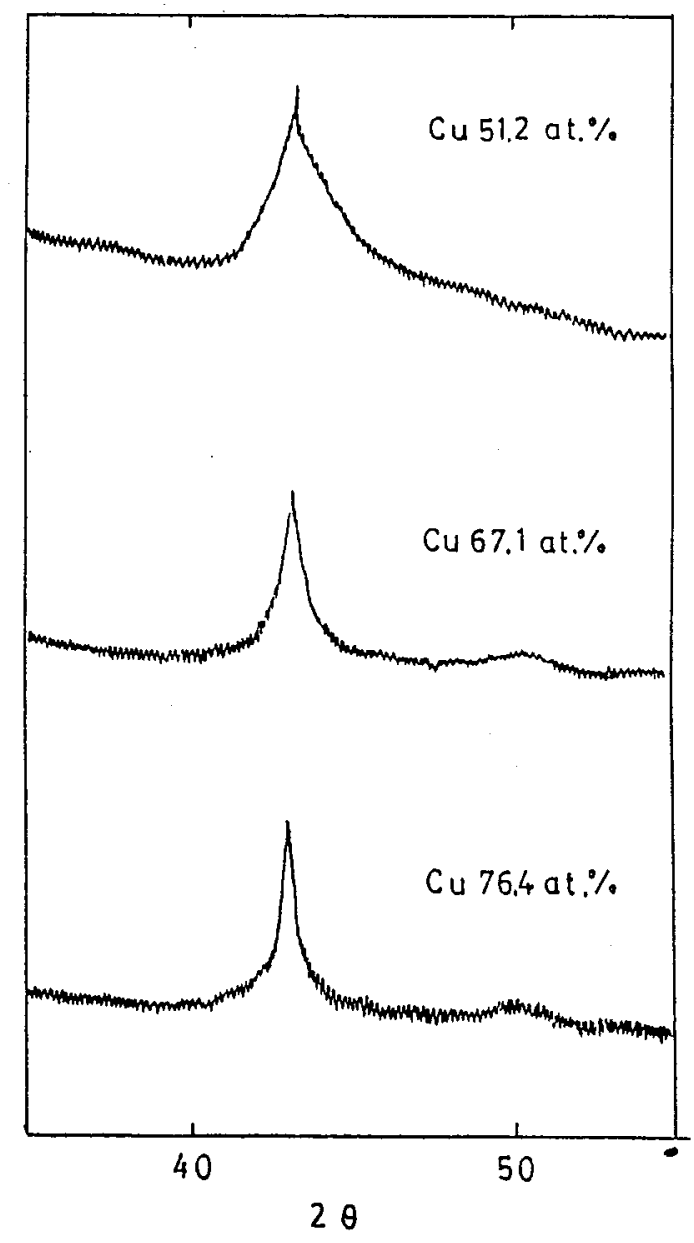

Fig. 4 Dependence of X-ray diffraction diagrams on $\mathrm{Cu}$ content (Part 2)

iron atoms reduced against the increase of $\mathrm{Cu}$ content. However, the shift of 6 absorption lines cannot be found at least in the region of $\mathrm{X}_{\mathrm{Cu}}$ of 0 to 15.3 at.\%. Accordingly, it cannot be thought that the value of the internal magnetic field changed due to the difference of the composition of the thin films in the bccphase dominant region. However, it is presumed that the distribution of the internal magnetic field spread since the spectrum width became broader compared to the case of pure iron.

Figure 8 shows the $\mathrm{Cu}$ content $\mathrm{x}_{\mathrm{Cu}}$ 


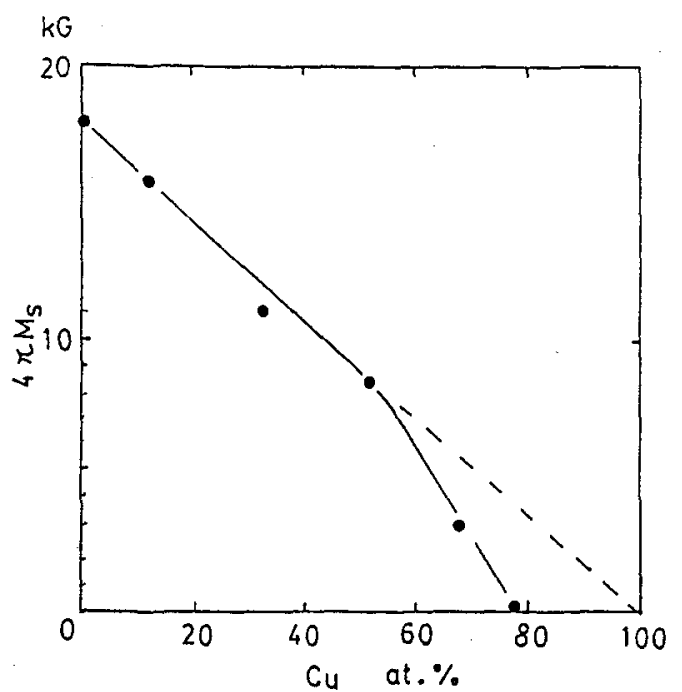

Fig.5 Dependence of saturation magnetization $4 \pi \mathrm{Ms}$ or $\mathrm{Cu}$ content

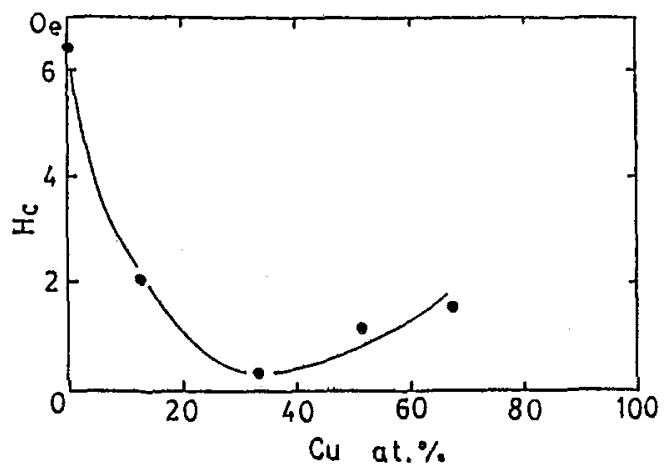

Fig.6 Dependence of coercivity Hc on $\mathrm{Cu}$ content

dependence of coercivity $\mathrm{HC}$ of the thin films deposited by the RF Sputtering (RFS) and the IBS. Hc of the thin films prepared by the RFS was much larger than that by the IBS. In the case of the RFS, $\mathrm{Hc}$ was about 10 Oe even at a minimum value. This seems to be due to the reason that in the case of the IBS, the thin films hardly included impurities and hardly damaged since they can be deposited on plasma-free substrates at considerably

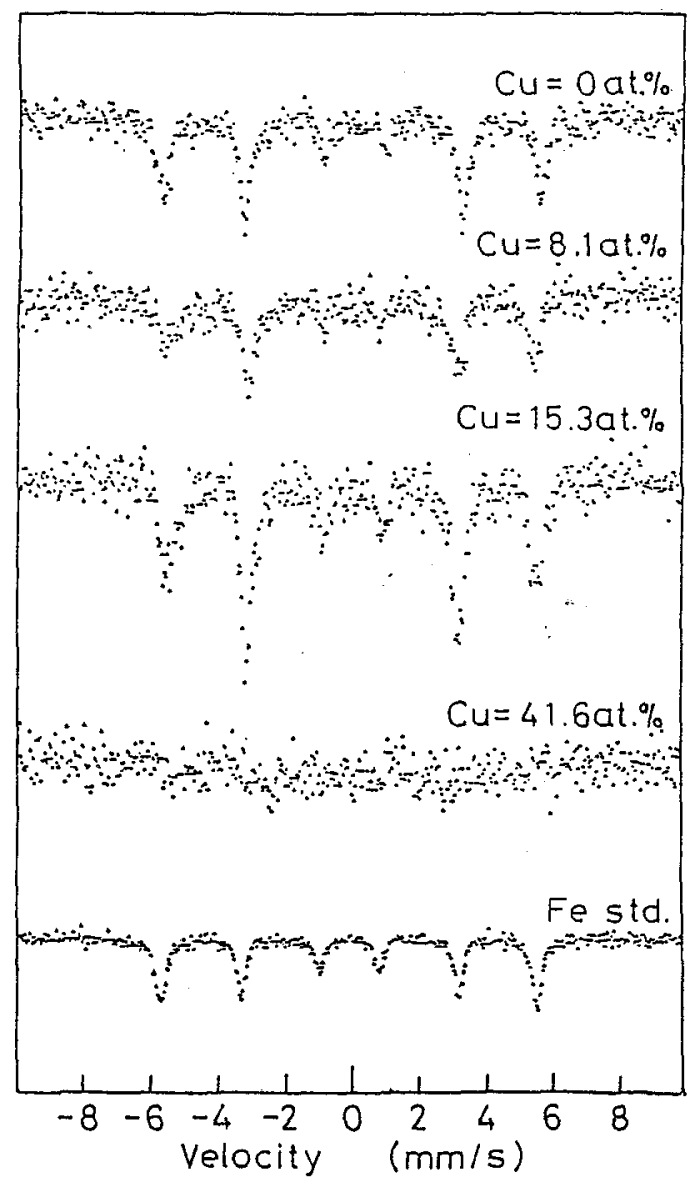

Fig.7 Dependence of Moessbauer spectra on $\mathrm{Cu}$ content

lower argon gas pressure compared to the RFS.

Figures 9 and 10 show Moessbauer spectra of the thin films prepared by the RFS and the Facing Target Sputtering (FTS)[4], respectively. In every sputtering method, 6 absorption lines, which are characteristic of ferromagnetic substances, can be observed in the bccphase dominant region less than 40 at.\%Cu. First, concerning the position of absorption lines, there is no difference between deposition methods. So, it can be recognized that there is scarcely 


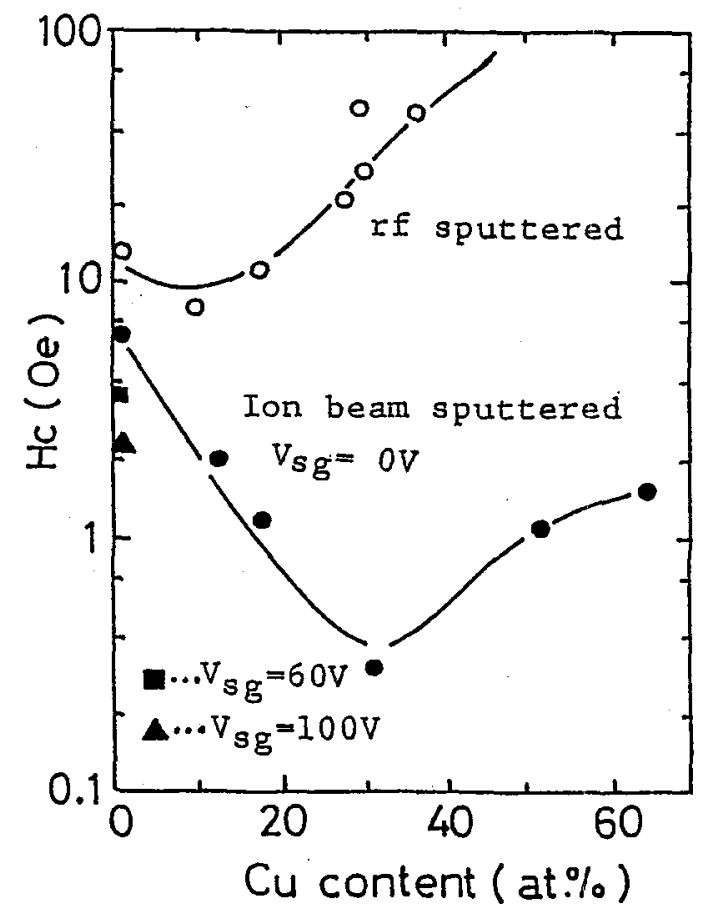

Fig.8 Dependence of coercivity Hc on $\mathrm{Cu}$ content

difference on the internal magnetic field between them. However, concerning the intensity ratios, it is obvious that there is difference. As for IBS, the 2nd and 5 th absorption lines are very intensive, while these two absorption lines are weak in the RFS and FTS. This indicates that the magnetization of the thin films by the IBS is in the in-plain direction, while that by the RFS and the FTS is in the perpendicular one to the film surface. Furthermore, in the fccdominant, higher- $\mathrm{X}_{\mathrm{Cu}}$ region, the spectra include one absorption line, which shows paramagnetism.

This corresponds to that $4 \pi \mathrm{Ms}$ showed the lower value than that estimated due to the simple dilution law in the region over 50 at. $\% \mathrm{Cu}$ in Fig.5. In addition, this coincides with the report that the magnetic moment per one iron atom is constant in the bec-phase region, but this moment would decrease remarkably with the

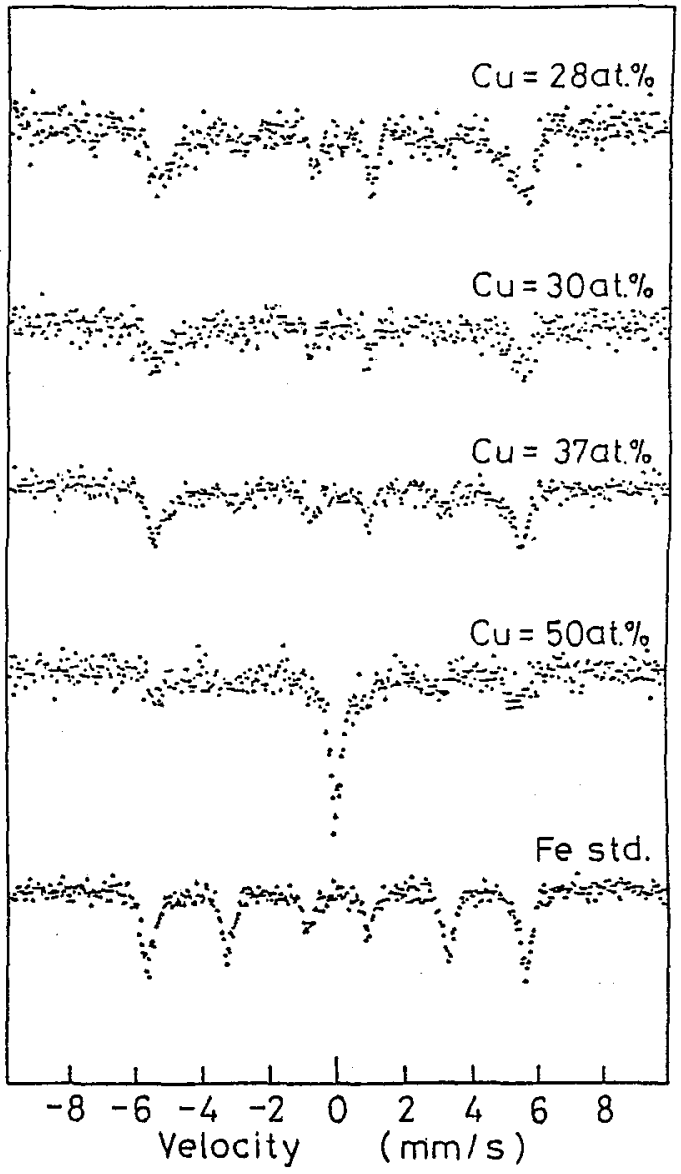

Fig.9 Dependence of Moessbauer spectra of RF sputtered films on $\mathrm{Cu}$ content

increase of the $\mathrm{Cu}$ content in the fccphase region[5].

In order to test the chemical stability, specimen films were put in saturated water vapor or dipped in water at room temperature. After being kept in both conditions for more than 1 month, the films deposited with the suitable-energy ion bombardment $(\mathrm{Vsg}=100 \mathrm{~V}) \mathrm{did}$ not rust and did not exhibit any change in their magnetic properties. Therefore, the DIBS system is very useful for preparing the $\mathrm{Fe}-\mathrm{Cu}$ thin films with soft magnetic properties and good chemical stability. 


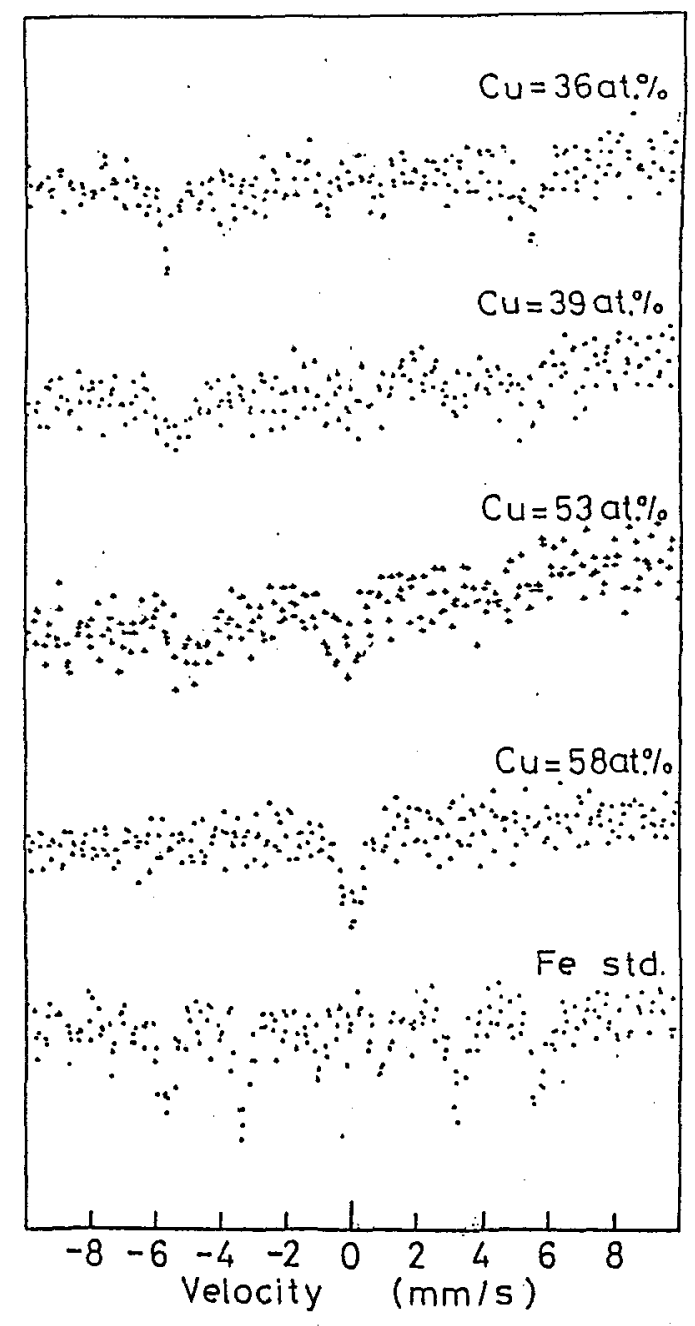

Fig.10 Dependence of Moessbauer spectra of Facing-Target sputterd films on $\mathrm{Cu}$ content

\section{CONCLUSION}

The $\mathrm{Fe}-\mathrm{Cu}$ thin films deposited by the DIBS system have very useful properties for soft magnetic layers in magnetic recording devices. First, the structure of the $\mathrm{Fe}-\mathrm{Cu}$ thin films was amorphous-like, bcc and fcc phases for $X_{C u}$ in the ranges of 0 to 10,10 to 40 and more than 40 at.\%, respectively. Second, in the bcc- phase region $4 \pi \mathrm{Ms}$ decreased along the simple dilution law and $\mathrm{Hc}$ deceased monotonically. Third, in the fcc-phase region $4 \pi M s$ decreased remarkably more than the value estimated due to the abovementioned law and $\mathrm{Hc}$ began to increase. Fourth, the excellent, soft magnetic $\mathrm{Fe}^{-}$ $\mathrm{Cu}$ thin films were obtained at 32.8 at.\%Cu, where $4 \pi \mathrm{Ms}$ was 11.4 KGauss and $\mathrm{Hc}$ was 0.3 Oe. Finally, the films deposited with the ion bombardment exhibited good chemical stability, which did not rust and did not exhibit any change in magnetic properties, even after being kept in saturated water vapor for more than 1 month. Consequently, the $\mathrm{Fe}-\mathrm{Cu}$ thin films deposited by the DIBS system is very useful for soft magnetic layers in magnetic recording devices.

\section{REFERENCES}

[1]M.Hansen and K.Anderko,"Constitution of Binary Alloys"(McGraw-Hill),pp580(1958).

[2]M.Naoe, M.Yamaga and N.Terada, IEEE Trans. on Magn., MAG-21, 1900(1985).

[3]M.Naoe and N.Terada, Oyo Buturi, 55, $119(1986)$.

[4]T.Hirata and M.Naoe, ICF-5(Bombay), C4-06 in Proceedings (to be published).

[5]K.Sumiyama, T.Yoshitake and y.Nakamura, J. Phys. Soc. Japan,53, No.9(1984). 